Çukurova Üniversitesi Mühendislik Fakültesi Dergisi, 36(1), ss. 43-53, Mart 2021

Cukurova University Journal of the Faculty of Engineering, 36(1), pp. 43-53, March 2021

\title{
Güç Tutuşurluk Apresinin Denim Kumaş Performans Özelliklerine Etkisinin Araştırılması
}

\author{
PInar DURU BAYKAL ${ }^{* 1}$, Eda KARATAŞ ${ }^{1}$ \\ ${ }^{1}$ Çukurova Üniversitesi, Mühendislik Fakültesi, Tekstil Mühendisliği Bölümü, Adana
}

Geliş tarihi: 29.01.2021 Kabul tarihi: 31.03.2021

$\ddot{\mathbf{O z}}$

Bu çalışmanın amacı, performans özelliklerini (hava geçirgenliği, yırtılma mukavemeti ve yumuşaklık) kaybetmeden güç tutuşur denim kumaş üretmektir. Bu amaçla 4 farklı ön terbiye işlemine tabi tutulmuş 8 farklı kumaş numunesi üretilmiştir. Güç tutuşurluk özelliği, kumaşın alev geciktirici kimyasal ile terbiyesine göre elde edilmiştir. Ayrıca apreli kumaşlara 5 tekrarlı rins yıkama uygulanmıştır. Sonuçlar, sinırlı alev yayılma testi, hava geçirgenlik testi, yırtılma mukavemeti testi ve yumuşaklık testleri yapılarak değerlendirilmiştir. Elde edilen sonuçlara göre güç tutuşurluk apresi yapılan numunelerde alevlenme, parlama veya delik oluşumu gözlenmemiştir. Genel olarak apre ve tekrarlanan yıkama işlemlerinin hava geçirgenlik değerlerini bir miktar düşürdüğü ancak ön terbiye işlemleri farklı olan bazı numunelerde değişiklik olmadığı görülmüştür. Tüm numunelerde güç tutuşurluk apresi sonrası yumuşaklık bir miktar azalmış ve kumaşlar sertleşmiş̧ir. Apreli kumaşların yıkanmasından sonra genel olarak yumuşaklık değerlerinde artı̧̧ gözlenmiştir.

Anahtar Kelimeler: Güç tutuşurluk, Denim kumaş, Sınırlı alev yayılımı testi, Güç tutuşurluk apre yöntemleri

\section{Investigation on the Effect of Flame Retardant Finishing on Denim Fabric Properties}

\begin{abstract}
The aim of this study is to produce flame retardant denim fabric without losing the performance features (air permeability, tear strength and softness). For this purpose, 8 different fabric samples with 4 different pretreatment processes were produced. The flame retardant property was obtained according to the method of treating the fabric with chemical that provides flame retardancy. In addition, 5 repetitive rins washing was applied to the finished fabrics. The results were evaluated by performing limited flame spread test, air permeability test, tear strength test and stiffness tests. According to the results obtained no flaming, glowing or hole formation was observed in the samples with flame retardant finishing. In general, it was observed that finishing and repeated washing processes slightly decreased the air permeability values, but there was no change in some samples according to the pretreatment processes. In all samples, softness decreased a little after flame retardant finishing, and fabrics became stiff. After washing the finished fabrics, an increase was observed in the softness values in general.
\end{abstract}

Keywords: Flame retardancy, Denim fabric, Air permeability, Limited flame spread, Flame retardancy methods

*Sorumlu yazar (Correspondingauthor): Pinar DURU BAYKAL, pduru@ cu.edu.tr 


\section{GíRiş}

Son yıllarda nüfus artışı ile toplu yaşam alanlarının çoğalması ve gelişen teknoloji ile dünyada yangın tehlikesi yüksek oranlara ulaşmıştır. Yangınların başlaması ve hızlı ilerlemesi genelde ortamda bulunan tekstil ürünlerinden kaynaklanmaktadır. Ayrıca yangınlarda can kaybı sayısı da insanların giysilerinin hızlı tutuşması nedeniyle artmaktadır.

Güç tutuşur özellikli koruyucu teknik tekstil grubuna dâhil olan giysiler, termal yönden yalıtkan ve su buharı geçirmez özelliktedir ve bu yüzden kullanıcı rahatsızlık duyar ve 1 sı stresine maruz kalır. Vücut sıcaklığı arttıkça kullanıcı terleme olayına maruz kalır ve konforsuz bir ortam yaratılmış olur. $\mathrm{Bu}$ sebeple son dönemlerde kullanıcı konforunu sağlayacak olan termal koruyucu giysiler üretimi üzerine araştırmalar yapılmaktadır [1].

Yüksek 1sı ve aleve karşı koruyucu teknik tekstiller; 1sıya, aleve, eriyen metallerin sıçramalarına, radyasyona ve aşırı soğuğa karşı koruma sağlayan giysilerdir. Aleve ve ssıya maruz kalmaya karşı koyan ya da aşırı çevre koşullarında 1sı transferine karşı yalıtım sağlayan bütün materyaller termal koruyucu giysi olarak adlandırılır. Petrokimya çalışanları, elektrik işçileri, dökümhaneler ve yüksek 1sı karşısında çalışan bütün işçilerin giysileri yüksek 1sı ve alevden koruyucu nitelikte olmalıdır [2]. Güç tutuşurlukla ilgili ev tekstilinde, iş yerlerinde, toplu taşıma araçlarında ve kamuya açık yerlerde kullanılan ürünler için bazı mevzuatlar ve düzenlemeler yapılmaktadır.

Bir tekstil ürününe güç tutuşur özellik kazandırmak için, yanma esnasında açı̆̆a çıkan 1s1 miktarını düşürmek veya harcanan enerjiyi artırmak gerekmektedir. Yani piroliz mekanizmasını değiştirerek ya da yanmayı frenleyici ürünler kullanarak tutuşması gereken enerjiyi arttırmak gerekmektedir.

Güç tutuşur kumaş elde etmek için literatürde bilinen farklı yöntemler vardır. Bunlar; yapısı itibariyle güç tutuşan teknik liflerin kullanılması, liflerin yapılarının değiştirilmesi, sentetik polimere lif çekimi esnasında güç tutuşma sağlayıcı kimyasalların ilave edilmesi, kumaş halindeki tekstil ürününün güç tutuşma sağlayan kimyasallar ile muamele edilmesi şeklinde sayılabilir.

$\mathrm{Bu}$ yöntemlerin tümü de tekstil sektöründe geniş çaplı olarak kullanılmaktadır. Kumaşın kullanım alanına göre bu yöntemler tek tek ya da birlikte kullanılarak en iyi güç tutuşma sergileyecek değişik kumaş yapıları elde edilebilmektedir. Güç tutuşur kumaşlar genelde uzay, uçak, petro-kimya, çelik endüstrisi gibi yüksek koruyuculuk gerektiren sanayi dallarında kullanılmaktadır [3].

Son yıllarda daha az maliyetli ve çevre dostu güç tutuşur maddelerin üretimi ve kullanımı ile ilgili çalışmalar artmıştır. Halojen içermeyen güç tutuşur maddelerin kullanımı yaygınlaşmış ayrıca penta ve oktabromdifenil eterin kullanımı tamamen yasaklanmıştır. Yeni yöntemler olarak; plazma işlemi ile yüzey modifikasyonu, mikrokapsül uygulamaları ve nanoteknoloji son çalışmalarda öne ç1kmaktadır [4-7].

Yanma 3 aşamadan oluşur bunlar; materyalin 1sınması, makro moleküllerin termik olarak parçalanması (piroliz), tutuşma ve yanmanın başlamasıdır. Ürünün özgül 1s1, 1s1 iletkenliği, erime 1sısı gibi özelliklerine bağlı olarak ürüne enerji verilmesi durumunda, ürünün 1sınmas1 (yüzey sıcaklığının artması) değişiklik gösterir. Ürünün özelliğine göre yüzey sıcaklığg belirli bir noktaya ulaştığında piroliz olayı başlar. Piroliz olayı sirasında, artan sicaklığın etkisiyle önce yavaş olan pirolizin hızlanmasıyla ortamda yanıcı gaz karışımı oluşmakta ve ürün kendiliğinden tutuşabilmektedir [8].

Kumaşlarda güç tutuşurluk özelliğinin değerlendirilmesi açısından göz önünde bulundurulması gereken çok sayıda parametre bulunmaktadır. Materyalin yanma davranışı, alevin çıkış kaynağı, materyalin yüzey yapısı gibi değişkenlere bağlı olarak geliştirilmiş çok sayıda test metodu yapılabilmektedir. $\mathrm{Bu}$ standartlardan piyasada en çok kullanılanları aşağıdaki gibi sayabiliriz:

1. Malzemenin bulunuş konumuna göre; dikey yakma testi, havlı ve havsız yer döşemeleri 
için dikey yakma testi, yatay yakma testi, $45^{\circ}$ 'lik eğik yanma testi,

2. Yanmanın kaynağına bağlı olarak sigara test yöntemi, butangaz testi, yanma için ortamda gerekli olan oksijen miktarının tespiti için LOI (Limited Oxygen Index) testi,

3. Yanma sırasında açığa çıkan toksikliğin belirlenmesinde kullanılan toksisite testi,

4. Malzemenin yanma davranışına göre tutuşma kolaylığı testi ve alev yayılma testi.

Güç tutuşurluk testlerinde kullanılan yöntem ne olursa olsun tutuşturma kaynağı uzaklaştırıldıktan sonraki yanma süresi, alevli yanma bittikten sonraki içten yanma süresi, test sonunda oluşan kömürleşme boyu ve alanı, yanmanın ilerleme hızı, damlama olay1, zehirli / zehirsiz gaz veya duman çıkarma durumu genel değerlendirmede göz önünde bulundurulması gereken önemli konulardandır $[9,10]$.

\section{2. ÖNCEKİ ÇALIŞMALAR}

Beyit, çalışmasında koruyucu giysilerin tanımı ve sınıflandırılması, tarihi gelişimi, üretiminde kullanılan lifler, kullanım alanları ve uygulanan test standartları ile ilgili bilgilere yer vermiştir. Çalışmada, koruyucu giysilerde kullanılan lifler olarak yüksek performanslı lifler, güç tutuşur polinozik, PES, poliamid ve PAN lifleri açıklanmıştır [2].

Kalın, çalışmasında yanmayı geciktirici bir kimyasal olan Alfa-x isimli kimyasala borlu bileşikler ilave edilerek kumaşların güç tutuşurluk özelliklerinin artırılmasını amaçlamıştır. Kumaşların güç tutuşurluk özelliğinin borlu bileşiklerle arttırılabileceği belirtilmiştir [8].

Gemci ve arkadaşları, çalışmalarında; \%100 poliesterden oluşan perdelik kumaşa güç tutuşur özellik kazandırılması amacıyla denemeler yapmışlardır. Çalışmada poliester kumaşa çektirme yöntemi ile dispers boyama işlemi yapılmıştır. Boyama çözeltisi içerisine çeşitli oranlarda borik asit ve boraks dekahidrat çözeltileri ilave edilmiştir. Sonrasında numunelere; dikey yanma testi, spektrofotometre ile renk ölçümü testi, ışığa ve yıkamaya karşı renk haslığı testleri uygulanmıştır [3].

Ömeroğulları ve arkadaşları, çalışmalarında emdirme yöntemi ile doğal yapıda güç tutuşur madde kullanarak poliester kumaşa güç tutuşur özellik kazandırmışlardır. FTIR (ATR) ve SEM kullanılarak, işlem görmüş olan polyester kumaşın fiziksel yüzey özelliği analiz edilmiş olup; LOI ölçümü ile de güç tutuşurluk özelliği değerlendirilmiştir [11].

Horrocks tarafından yapılan çalışmada, 1950-1980 yılları arası güç tutuşurluktaki altın çă̆ 1980-1990 yılları arası yapılan geliştirmeler ve 2000 yılından sonraki gelişmeler anlatılmıştır. Ayrıca nano teknoloji uygulamaları, nano kompozit lifler, plazma teknolojisi konuları incelenmiştir [4].

Çakal ve arkadaşları, borun pamuklu kumaşlar üzerindeki güç tutuşurluk özelliğini araştırmışlardır. Güç tutuşurluk çözeltisi hazırlanırken üç farklı bor bileşiği ile fosfor bileşiği ve üre bazlı bir bağlayıcı kullanılmıştır [12].

Gültekin ve arkadaşları, SeaCell ${ }^{\circledR}$ active ve SeaCell ${ }^{\circledR}$ pure ipliklerden üretilen medikal ve ekolojik olarak bilinen kumaşların güç tutuşurluk özelliklerini araştırmışlardır [13].

Ertekin ve arkadaşları, çalışmalarında para-aramid, meta-aramid ve FR PES (güç tutuşur poliester) esaslı olmak üzere üç farklı lif tipinden ve üç farklı numarada (Ne 10, 20, 30) atk1 iplikleri ile üretilen kumaşlar ve çözgü ipliği olarak ise Ne 30/2 para aramid ipliklerinden oluşan kumaşlarla çalışmışlardır. Farklı iplik numarası ve farklı lif tipinden oluşan kumaşların yanma davranışı ve mekanik özellikleri istatistiksel olarak incelenmiştir [14].

Bütüner, çalışmasında $\% 50$ poliester ve $\% 50$ pamuktan oluşan kumaşta halojen içermeyen, fosfor ve azot bazlı güç tutuşur madde ile yapılan güç tutuşurluk bitim işlemlerini incelemiştir. Çalışmada fosfor ve azot bazlı kimyasallar kullanılarak güç tutuşurluk elde edilmiş ancak yıkama dayanımlarının olmadığı gözlemlenmiştir. 
Kimyasallarla kombinasyon yapılarak oluşturulan çözeltilerin ise güç tutuşurluğu olumsuz yönde etkilediği ve yıkama dayanımını arttırmadığı gözlemlenmiştir [15].

Aksöz, çalışmasında pamuklu kumaşların güç tutuşurluğunu arttırmak amacı ile çinko borat ve fosfor esaslı kimyasal içeren yeni malzemeler geliştirmeye çalışmıştır. Çalışma kapsamında tane boyutu düşürülerek kararlı apre solüsyonu haline getirilen fosfor esaslı malzeme ile çok iyi güç tutuşur özellik elde edilebilmiştir. Fosfor esaslı malzemeler ile sinerjik etki sağlayabileceği düşünülen çinko borat ile istenen özellik elde edilememiştir [16].

Cayla ve arkadaşları, çalışmalarında biobazlı polimerlerden biri olan polilaktik asit (PLA)'ya güç tutuşur özellik kazandırmak için ağırlıklı olarak asit ve karbon içeren bir formülasyon eklemişlerdir. Çalışmada çeşitli PLA multiflamentlerine bariyer oluşturma özelliği kazandırılmış ve amonyumpolifosfat formlasyonları ilave edilerek PLA' nın güç tutuşurluk özelliği üzerinde denemeler yapılmıştır [17].

Avcı ve arkadaşları tarafından yapılan çalışmada poliproplene güç tutuşurluk özelliği (alev geciktiricilik) kazandırmak amacıyla kullanılan katkı malzemeleri incelenmiş, bu alandaki güncel gelişmelere ve gelecekteki beklentilere değinilmiştir. Güç tutuşurluk özelliği kazandıran malzemeler halojen içerenler, şişen sistemler, fosfor esaslilar, metal hidroksitler, nano malzemeler ve silikon içerenler olarak gruplandırılmıştır [18].

Şardağ, çalışmasında farklı karışım oranlarında pamuk, tencel ve yap1sı itibarı ile 1s1 ve alev direnci yüksek olan meta-aramid içeren örme kumaşların konfor özelliklerini araştırmıştır. Bu amaçla meta-aramid iplikler ile pamuk, tencel ve tencel/ pamuk iplikler katlanarak 4 farklı karışım oranına sahip iplik ve örme kumaş elde edilmiştir. Yapılan çalışmanın sonucunda karışımda tencel ve pamuk oranının değişmesiyle kumaşların mukavemet ve konfor özelliklerinin değiștiği ve güç tutuşur kumaşlarda tencel lifinin konfor özelliklerini arttırmak için iyi bir alternatif olabileceği sonucuna varılmıştır [19].

Akşit ve arkadaşları, çalışmalarında çinko borat ve alüminyum hidroksit gibi toksik olmayan inorganik bileşikler ile konvansiyonel polimerik kaplamalar ve azot-fosfor bileşikleri gibi çevre dostu bileşikler ile sol-jel nano kaplamalar elde etmişlerdir. Çalışmada ticari olmayan güç tutuşur maddeler kullanılarak endüstriyel ölçeğe uyarlanabilir şekilde elde edilen güç tutuşur tekstil materyalleri, kullanılan kimyasal madde miktarı, güç tutuşurluk ve termal bozunma sonucunda ortaya çıkan toksik gaz salınımı bakımından karşılaştırmalı olarak değerlendirilmiştir [20].

Önder, çalışmasında yuvarlak örme makinelerinde $\% 100$ Poliester (PET) yatak kumaşı üretip daha sonra üretilen bu kumaşlara, emdirme ve köpük kaplama yöntemlerine göre güç tutuşurluk kimyasalları uygulamıştır. Emdirme yönteminde güç tutuşurluk kimyasalının miktarı, fikse sıcaklığı ve sıkma basıncı parametreleri, köpük kaplama yönteminde ise köpük yoğunluğu ve fikse sıcaklığı parametreleri değiştirilerek örme kumaşı üzerindeki güç tutuşurluk etkileri analiz edilmiştir [21].

Eyi tarafından yapılan çalışmada, \% 99 pamuk \% 1 elastan içeren denim kumaşın termal direncini arttırmak ve yüksek güç tutuşurluk özellik kazandırmak için borik asit, boraks, nano $\mathrm{SiO}_{2}$, fosfor ve azot bileşimlerinin (CTAP) her biri ayrı ayrı ticari apre çözeltisine ilave edilerek apre çözeltileri hazırlanmıştır. Hazırlanan çok bileşenli apre çözeltileri kumaş numunelerine boyama sonrası bitim işlemi olarak uygulanmıştır. Denim kumaş yüzey özellikleri SEM-EDX ölçümleri ile yorumlanmıştır [22].

Kaynak ve arkadaşları tarafından yapılan çalışmada yün ve yün/poliamid karışımı örme kumaşlara zirkonyum bileşikleri ile çektirme yöntemine göre güç tutuşurluk apresi uygulanmış ve sonuçlar değerlendirilmiştir. \% 100 yün kumaş, yalnızca $\% 1$ potasyum heksaflorozirkonat ve $\%$ 10 zirkonyum asetat çözeltisi ile işlendiğinde dikey yanıcılık testini geçebilmiştir [23]. 
Tekstilde güç tutuşurluk konusunda pek çok çalışma olmasına karşın, denim kumaşta güç tutuşurluk ile ilgili çok az çalışmaya rastlanmıştır. $\mathrm{Bu}$ çalışmada dayanıklılığ 1 ve rahatlığıyla işçilerin genellikle tercih ettiği ve her yaştan her kesimden talep gören denim kumaşa güç tutuşurluk özelliği kazandırılması amaçlanmıştır.

Güç tutuşurluk birçok alanda istenen bir özellik olmasına rağmen henüz yaygınlaşmamıştır. $\mathrm{Bu}$ yüzden güç tutuşurluğu dünya çapında çok yaygın kullanılan kumaş çeşidi olan denim kumaşa uygulamak, bu teknik özelliği hayatımıza sokmak için önemli bir gelişme olacaktır.

Genelde güç tutuşurluk gibi kumaşa teknik özellik kazandıran aprelerin kumaşın performans ve tutum özelliklerini olumsuz olarak etkilediği gözlemlenmiştir. $\mathrm{Bu}$ yüzden bu çalışmada denim kumaşlara oldukça önemli performans özellikleri olarak kabul edilen hava geçirgenliği, yırtılma mukavemeti ve yumuşaklık derecesi tayini yapılmıştır.

Denim kumaşlara genellikle yıkama işlemleri uygulandığından, güç tutuşurluk apresinden sonra tekrarlı rins yıkama da yapılmıştır.

\section{MATERYAL VE METOT}

\subsection{Materyal}

Çalışmada iki ayrı konstrüksiyonda, $200 \mathrm{~cm}$ tarak eninde ve 3/1 $\mathrm{Z}$ dimi örgüsünde denim kumaş üretilmiştir. Dokumadaki çözgü iplikleri \%100 pamuk ring karde iplikleridir. Ring karde atk1 ipliklerinin hammaddesi ise ilk dört numune için $\% 98$ pamuk-\%1 PBT-\%1 elastan, son dört numune için ise $\% 98$ pamuk-\%2 elastandır.

Numune kumaşların konstrüksiyon bilgileri Çizelge 1'de verilmiştir. Kumaşlara 4 ayrı ön terbiye işlemi uygulanarak 8 farklı numune elde edilmiştir [24].
Çizelge 1. Numunelerin konstrüksiyon bilgileri

\begin{tabular}{|c|c|c|c|c|c|c|}
\hline \multirow{2}{*}{$\begin{array}{l}0 \\
\mathbf{Z} \\
\stackrel{\Xi}{\Xi} \\
\mathbf{\Xi} \\
\mathbf{Z} \\
\mathbf{Z}\end{array}$} & \multirow[b]{2}{*}{ 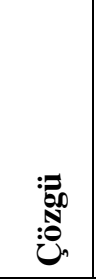 } & \multirow[b]{2}{*}{$\sum^{\frac{5}{2}}$} & \multirow{2}{*}{ 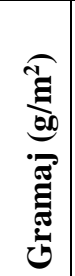 } & \multirow{2}{*}{ 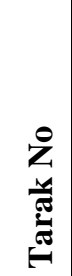 } & \multicolumn{2}{|c|}{ 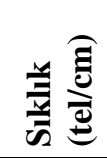 } \\
\hline & & & & & 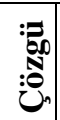 & $\sum^{ \pm}$ \\
\hline 1 & $\mathrm{Ne} 6$ & $\mathrm{Ne} 10 \mathrm{CO} / \mathrm{PBT} / \mathrm{EA}$ & 415 & $42 / 4$ & 17 & 14 \\
\hline 2 & $\mathrm{Ne} 6$ & Ne10 CO/PBT/EA & 415 & $42 / 4$ & 17 & 14 \\
\hline 3 & $\mathrm{Ne} 6$ & $\mathrm{Ne} 10 \mathrm{CO} / \mathrm{PBT} / \mathrm{EA}$ & 415 & $42 / 4$ & 17 & 14 \\
\hline 4 & $\mathrm{Ne} 6$ & $\mathrm{Ne} 10 \mathrm{CO} / \mathrm{PBT} / \mathrm{EA}$ & 415 & $42 / 4$ & 17 & 14 \\
\hline 5 & $\mathrm{Ne} 10$ & $\mathrm{Ne} 10 \mathrm{CO} / \mathrm{EA}$ & 364 & $68 / 4$ & 27 & 17 \\
\hline 6 & $\mathrm{Ne} 10$ & $\mathrm{Ne} 10 \mathrm{CO} / \mathrm{EA}$ & 364 & $68 / 4$ & 27 & 17 \\
\hline 7 & $\mathrm{Ne} 10$ & $\mathrm{Ne} 10 \mathrm{CO} / \mathrm{EA}$ & 364 & $68 / 4$ & 27 & 17 \\
\hline 8 & $\mathrm{Ne} 10$ & $\mathrm{Ne} 10 \mathrm{CO} / \mathrm{EA}$ & 364 & $68 / 4$ & 27 & 17 \\
\hline
\end{tabular}

CO: Pamuk, PBT: PolibütilenTereftalat, EA: Elastan

\subsection{Metod}

Üretilen numune denim kumaşlara sıklıkla uygulanan ön terbiye işlemleri yapılmış ve isimleri aşağıda verilmiştir.

Numune 1 ve Numune 5: Yakma

Numune 2 ve Numune 6: Yakma, haşıl sökme, yıkama

Numune 3 ve Numune 7: Yakma, haş1l sökme, yıkama, merserize

\section{Numune 4 ve Numune 8: Merserize}

Deneysel çalışma sırasında 8 adet numuneye aynı güç tutuşur apre reçetesi uygulanmıştır. Bu reçetedeki kimyasallar emdirme yöntemiyle $20-25^{\circ} \mathrm{C}$ banyo sicaklığında uygulanmıştır. Ardından $130^{\circ} \mathrm{C}$ 'de 3 dakika kurutulup, $180^{\circ} \mathrm{C}$ 'de 1 dakika fiske yapılmıştır. Güç tutuşur apre reçetesi Çizelge 2'de verilmiştir [24].

Çizelge 2. Numunelere uygulanan apre reçetesi

\begin{tabular}{|l|l|}
\hline Apre Kimyasalı & Miktarı \\
\hline $\begin{array}{l}\text { RUCO-FLAM PCE } \\
\text { (apre kimyasalı) }\end{array}$ & $500 \mathrm{~g} / 1$ \\
\hline RUCON FAS-TR (bağlayıcı) & $40 \mathrm{~g} / 1$ \\
\hline Fosforik asit (\%85'lik) & $18 \mathrm{~g} / 1$ \\
\hline RUCOWET FN (1slatıcı) & $2 \mathrm{~g} / 1$ \\
\hline
\end{tabular}


Apre yapılan numunelerin yarısına 5 tekrarlı rins yıkama yapıldıktan sonra diğer yarısına ise yıkama yapılmadan güç tutuşurluk, hava geçirgenliği, yumuşaklık ve yırtılma mukavemeti testleri uygulanmıştır. Denim yıkamada sıklıkla uygulanan rins yıkama, $30 \mathrm{C}^{\circ}$ ' de 20 dakika boyunca 5 tekrarlı olarak su ile yapılmıştır.

Çalışmada güç tutuşurluk testi TS EN ISO 11612:2015 standardına [25] göre sinırlı alev yayılımı metodu ile yapılmıştır. Bu uluslararası standart dikey olarak yönlendirilmiş malzemenin alev yayılma özelliğini saptamak için kullanılır. Test için atkı ve çözgü yönünde 3'er numune alınmıştır. Deneyde kullanılan FlexiBurn test cihazı Şekil 1'de verilmiştir.

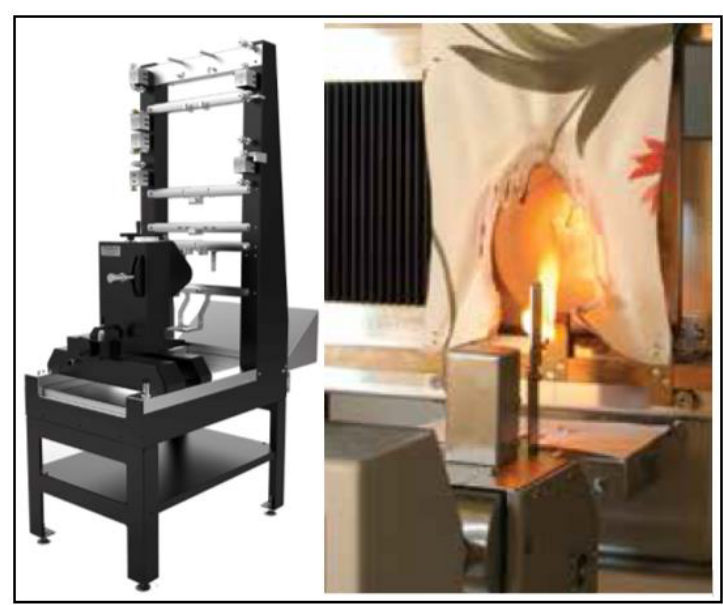

Şekil 1. Flexi Burn test cihazı [26]

Numunelerinin hava geçirgenlikleri TS 391 EN ISO 9237: 1999 standardına [27] göre belirlenmiştir. Buna göre hava geçirgenliği, kurulan deney düzeneğine uygun olarak yerleştirilen deney numunesinin iki yüzü arasından dik olarak geçen vakumlu havanın $\mathrm{mm} / \mathrm{sn}$ cinsinden ölçülen hızı olarak ifade edilmektedir. Her numune kumaş için 10 adet ölçüm yapılmıştır.

TS EN ISO 13937-1:2002 standardına [28] göre gerçekleştirilen yırtılma mukavemeti tayini, ani bir kuvvet uygulanırken önceden açılmış bir yırtığın ilerleyerek numune kumaşının tamamen ikiye ayrılması için gerekli olan yırtma kuvvetinin ölçülmesi şeklinde uygulanmıştır. Balistik sarkaç metodu denim kumaşlarda sıklıkla uygulandığı için bu yöntem seçilmiştir. Her numune kumaş için 5 atkı ve 5 çözgü yönünde ölçüm yapılmıştır.

Yumuşaklık derecesi tayininde, Dijital Pnömatik Stiffness cihazı kullanılarak, ASTM D 4032-94 [29] dairesel eğme test metodu esas alınmıştır. Her kumaştan 5 adet ölçüm yapılmıştır.

\section{BULGULAR VE TARTIŞMA}

Çalışma kapsamında üretilmiş olan 8 adet numuneye güç tutuşurluk apre işlemi uygulanmadan önce sınırlı alev yayılımı testi yapılmıştır. Sonuçlara göre numunelerde yanan döküntü yani kül oluşumu gözlemlenmemiştir. Ancak kumaşlarda parlama veya delikler gözlemlenmiştir ve 8 numune de testten kalmıştır. $\mathrm{Bu}$ standarda göre numunelerin testten geçmeleri için gerekli olan şartlar 10 saniye alev uygulama süresinde yanan döküntü ve kenarlara ulaşan alev, delik veya parlama olmamasıdır.

Çalışma kapsamında apreli ve ayrıca apreli yıkanmış numunelerin güç tutuşurluk test sonuçları aşağıdaki çizelgelerde verilmiştir.

Çizelge 3. Güç tutuşurluk test sonuçları (Numune 5 hariç diğerleri)

\begin{tabular}{|c|c|c|c|c|c|}
\hline Kriterler & Ap & & $\begin{array}{l}\text { Apre } \\
\text { Yıkar }\end{array}$ & $\begin{array}{l}\text { li ve } \\
\text { amış }\end{array}$ & $=$ \\
\hline Test yönü & Çözgü & Atk1 & Çözgü & Atk1 & ڤّل \\
\hline $\begin{array}{l}\text { Alev uygulama } \\
\text { süresi }\end{array}$ & $10 \mathrm{~s}$ & $10 \mathrm{~s}$ & $10 \mathrm{~s}$ & $10 \mathrm{~s}$ & $10 \mathrm{~s}$ \\
\hline Yanan döküntü & Hayır & Hayır & Hayır & Hayır & Hayır \\
\hline $\begin{array}{l}\text { Alev } \\
\text { çekildikten } \\
\text { sonra yanma } \\
\text { süresi } \\
\end{array}$ & $0 \mathrm{~s}$ & $0 \mathrm{~s}$ & $0 \mathrm{~s}$ & $0 \mathrm{~s}$ & $\leq 2 \mathrm{~s}$ \\
\hline $\begin{array}{l}\text { Alev } \\
\text { çekildikten } \\
\text { sonra korlaşma } \\
\text { süresi } \\
\end{array}$ & $0 \mathrm{~s}$ & $0 \mathrm{~s}$ & $0 \mathrm{~s}$ & $0 \mathrm{~s}$ & $\leq 2 \mathrm{~s}$ \\
\hline $\begin{array}{l}\text { Kenarlara } \\
\text { ulaşan alev } \\
\text { veya parlama } \\
\end{array}$ & Hayır & Hayır & Hayır & Hayır & Hayır \\
\hline Delik oluşumu & $0 \mathrm{~mm}$ & $0 \mathrm{~mm}$ & $0 \mathrm{~mm}$ & $0 \mathrm{~mm}$ & $\leq 5 \mathrm{~mm}$ \\
\hline Sonuç & Geçti & Geçti & Geçti & Geçti & Geçti \\
\hline
\end{tabular}


Çizelge 4. Güç tutuşurluk test sonuçları (Numune 5)

\begin{tabular}{|c|c|c|c|c|c|}
\hline \multirow{2}{*}{$\begin{array}{l}\text { Kriterler } \\
\text { Test yönü }\end{array}$} & \multicolumn{2}{|c|}{ Apreli } & \multicolumn{2}{|c|}{$\begin{array}{l}\text { Apreli ve } \\
\text { Yıkanmış }\end{array}$} & \multirow{2}{*}{ 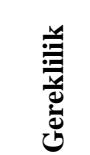 } \\
\hline & Çözgü & Atk1 & Çözgü & Atk1 & \\
\hline $\begin{array}{l}\text { Alev uygulama } \\
\text { süresi }\end{array}$ & $10 \mathrm{~s}$ & $10 \mathrm{~s}$ & $10 \mathrm{~s}$ & $10 \mathrm{~s}$ & $10 \mathrm{~s}$ \\
\hline Yanan döküntü & Hayır & Hayır & Hayır & Hayır & Hayır \\
\hline $\begin{array}{l}\text { Alev çekildikten } \\
\text { sonra yanma süresi }\end{array}$ & $0 \mathrm{~s}$ & $0 \mathrm{~s}$ & $6 s$ & $0 \mathrm{~s}$ & $\leq 2 \mathrm{~s}$ \\
\hline $\begin{array}{l}\text { Alev çekildikten } \\
\text { sonra korlaşma } \\
\text { süresi }\end{array}$ & $0 \mathrm{~s}$ & $0 \mathrm{~s}$ & $0 \mathrm{~s}$ & $0 \mathrm{~s}$ & $\leq 2 \mathrm{~s}$ \\
\hline $\begin{array}{l}\text { Kenarlara ulaşan } \\
\text { alev veya parlama }\end{array}$ & Hayır & Hayır & Hayır & Hayır & Hayır \\
\hline Delik oluşumu & $0 \mathrm{~mm}$ & $0 \mathrm{~mm}$ & $0 \mathrm{~mm}$ & $0 \mathrm{~mm}$ & $\leq 5 \mathrm{~mm}$ \\
\hline Sonuç & Geçti & Geçti & Kaldı & Geçti & Geçti \\
\hline
\end{tabular}

Test sonuçlarına göre apreli tüm numuneler testi geçmiş ve güç tutuşurluk özelliği kazanmıştır. Apreli ve yıkanmış numunelerden sadece Numune 5, testin bir aşamasından kalmıştır ancak testi genel olarak geçmiştir. Bu sonuçlara göre uygulanan güç tutuşurluk apresi tekrarlı rins yıkamaya karşı dayanıklıdır.

Güç tutuşurluk apresi uygulanmadan önce kumaşların hava geçirgenliği ölçülerek apre işleminden sonraki sonuçlarla karşılaştırılmıştır. Testler her kumaş türüne 10 adet olmak üzere tekrar edilmiştir. Her numuneden elde edilen saniye birimindeki verilerin ortalamaları alınıp $\mathrm{mm} / \mathrm{s}$ cinsinden hava geçirgenliği hesaplanmıştır. Çizelge 5'de ortalama hava geçirgenliği test sonuçları toplu olarak verilmiştir. Numunelerin hava geçirgenlik değişimleri ise Şekil 2'de gösterilmiştir.

Çizelge 5. Hava Geçirgenliği Test Sonuçları

\begin{tabular}{|c|c|c|c|}
\hline \multirow{2}{*}{$\begin{array}{c}\text { Numune } \\
\text { No }\end{array}$} & \multicolumn{3}{|c|}{ Hava Geçirgenliği R (mm/s) } \\
\cline { 2 - 4 } & Apresiz & Apreli & $\begin{array}{c}\text { Apreli ve } \\
\text { ylkanmış }\end{array}$ \\
\hline 1 & 215 & 165 & 105 \\
\hline 2 & 83 & 83 & 82 \\
\hline 3 & 69 & 75 & 83 \\
\hline 4 & 167 & 142 & 120 \\
\hline 5 & 334 & 210 & 133 \\
\hline 6 & 92 & 100 & 137 \\
\hline 7 & 92 & 92 & 101 \\
\hline 8 & 83 & 100 & 92 \\
\hline
\end{tabular}

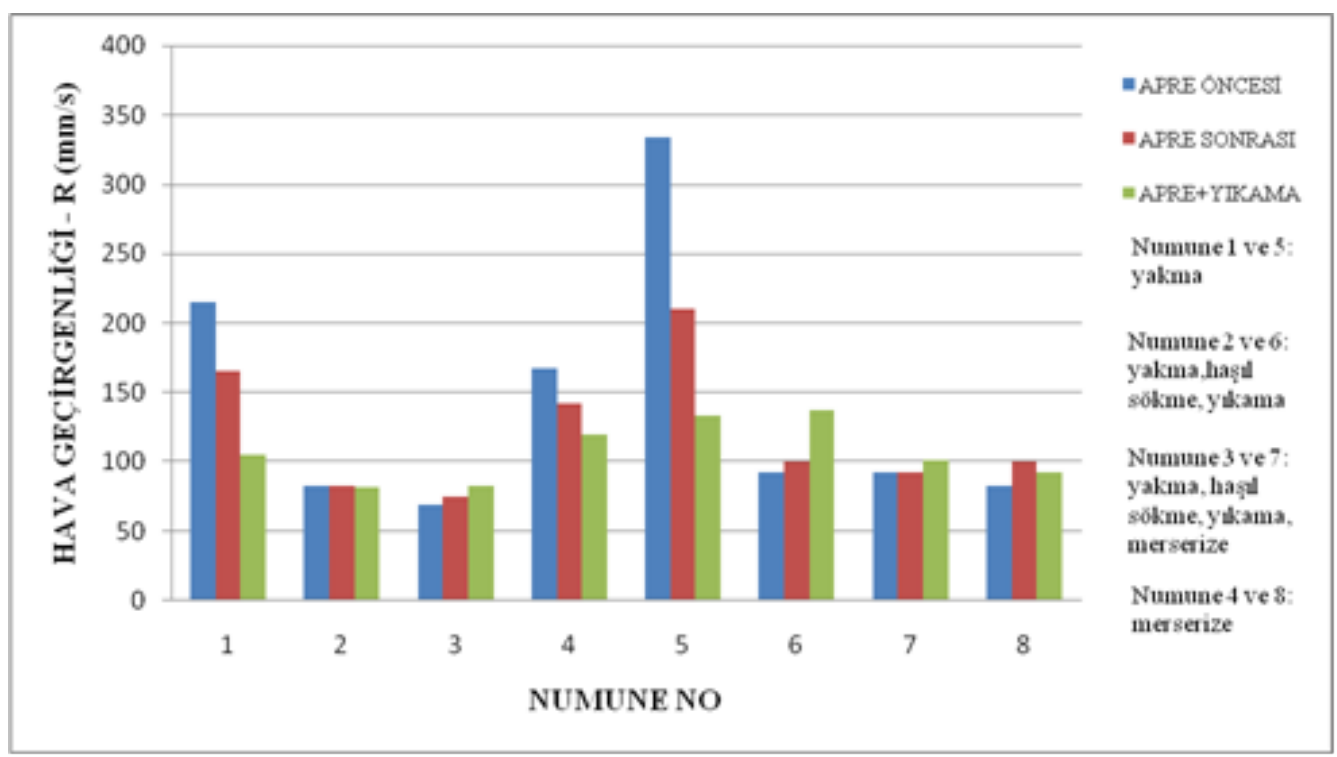

Şekil 2. Hava geçirgenliği değişimi 
İlk 4 numunenin atkı ve çözgü iplikleri ile konstrüksiyonları aynı olup, sadece ön terbiye işlemleri farklıdır. Benzer şekilde son 4 numune de gerek atkı ve çözgü iplikleri ve gerekse de konstrüksiyonları bakımından birbiri ile aynı olup ön terbiye işlemleri farklıdır.

Bu gruplar kendi içlerinde karşılaştırıldığında, sadece yakma işlemi yapılan kumaşların (Numune 1 ve Numune 5) hava geçirgenliği daha fazla çıkmıştır. Diğer ön terbiye işlemleri (haşıl sökme, yıkama ve merserize) yaş işlemler olduğundan kumaşların bir miktar çekmesi ve dokunun sıklaşması söz konusu olduğundan hava geçirgenliği değerleri de azalmıştır.

Ayrica Numune 1'e göre Numune 3 ve 4; Numune 5'e göre Numune 7 ve 8'in hava geçirgenlik değerlerinin düşük çıkması görmüş oldukları merserize işlemi ile açıklanabilir. Merserize işlemi ile pamuk liflerinin enine kesiti şişerek dairesel hal almakta ve böylece kumaş örtücülüğü artmaktadır. Dolayısıyla gözeneklilik azalacağından hava geçirgenliği de azalacaktır. Literatürde merserizasyon sonrası hava geçirgenliğinin azaldığı ifade edilmiştir [30].

Genel olarak apre işlemi sonrası kumaşın hava geçirgenliğinin düşmesi beklenir. Numune 1,4 ve 5'de beklenen bu durum gerçekleşmiştir. Özellikle Numune 1 ve 5'de bu düşüş çok daha fazla olmuştur. Ön terbiyede sadece yakma işleminin yapıldığı bu numunelerde, güç tutuşurluk apresinden sonra yani yaş işlem sonrası dokunun çekmesi beklenir ve bu durum ise hava geçirgenlik değerlerinde düşüşe yol açar.

Çözgü numuneleri $64 \mathrm{~N}$ 'luk yük altında uygulanan yırtılma mukavemeti testinde standarda uygun şekilde yırtılmamıştır. Çözgü iplikleri kalın olduğu için bu kuvvet yeterli olamamıştır. Atk1 yönünde ölçülen yırtılma mukavemeti değerlerinin ortalamaları Çizelge 6'da topluca verilmiş ve ayrıca Şekil 3'de grafik olarak gösterilmiştir. Atkı yırtılma mukavemet değerleri Numune 1 ve 5 dışında genel olarak güç tutuşurluk apresinden çok etkilenmemiştir. Ancak Numune 1 ve Numune 5'de apre sonrası mukavemette ciddi düşüş gözlenmiştir. $\mathrm{Bu}$ numunelere ön terbiyede sadece yakma işlemi uygulanmış ve yaş işlem yapılmamıştır, yani kimyasal bir işlem uygulanmadığından mukavemet kaybı da çarpıcı olmuştur. Yıkama sonrasında ise tüm numunelerde mukavemet düşüşü gözlenmiştir. Yıkama sonrası azalan mukavemet değerleri standartta belirtilen limit değerin altına düşmemiştir.

Çizelge 6. Yırtılma mukavemeti test sonuçları

\begin{tabular}{|c|c|c|c|}
\hline \multirow{2}{*}{$\begin{array}{c}\text { Numune } \\
\text { No }\end{array}$} & \multicolumn{3}{|c|}{ Atkı Yirtılma Mukavemeti (N) } \\
\cline { 2 - 4 } & Apresiz & Apreli & $\begin{array}{c}\text { Apreli ve } \\
\text { Yıkanmış }\end{array}$ \\
\hline 1 & 41,836 & 37,506 & 27,506 \\
\hline 2 & 35,004 & 35,870 & 16,548 \\
\hline 3 & 32,208 & 33,070 & 15,000 \\
\hline 4 & 59,146 & 59,680 & 32,962 \\
\hline 5 & 57,460 & 53,714 & 40,472 \\
\hline 6 & 53,726 & 51,936 & 21,928 \\
\hline 7 & 51,036 & 51,478 & 19,046 \\
\hline 8 & 41,508 & 40,012 & 21,928 \\
\hline
\end{tabular}

Elde edilen veriler, pamuklu blucin (denim) kumaşların tarifine, sınıflandırılmasına, özelliklerine dair bilgileri içeren TS 2791'e göre [31] belirlenen orta gramajdaki denim kumaşların sahip olması gereken en az atkı yırtılma mukavemeti değerinin (15 N) ve en az çözgü yırtılma mukavemeti değerinin $(35 \mathrm{~N})$ üzerindedir. Buna göre denim kumaşlara uygulanan güç tutuşurluk apresi ve sonrasında yapılan 5 tekrarlı rins yıkama işlemleri yırtılma mukavemeti açısından performans kaybına yol açmamıştır. 


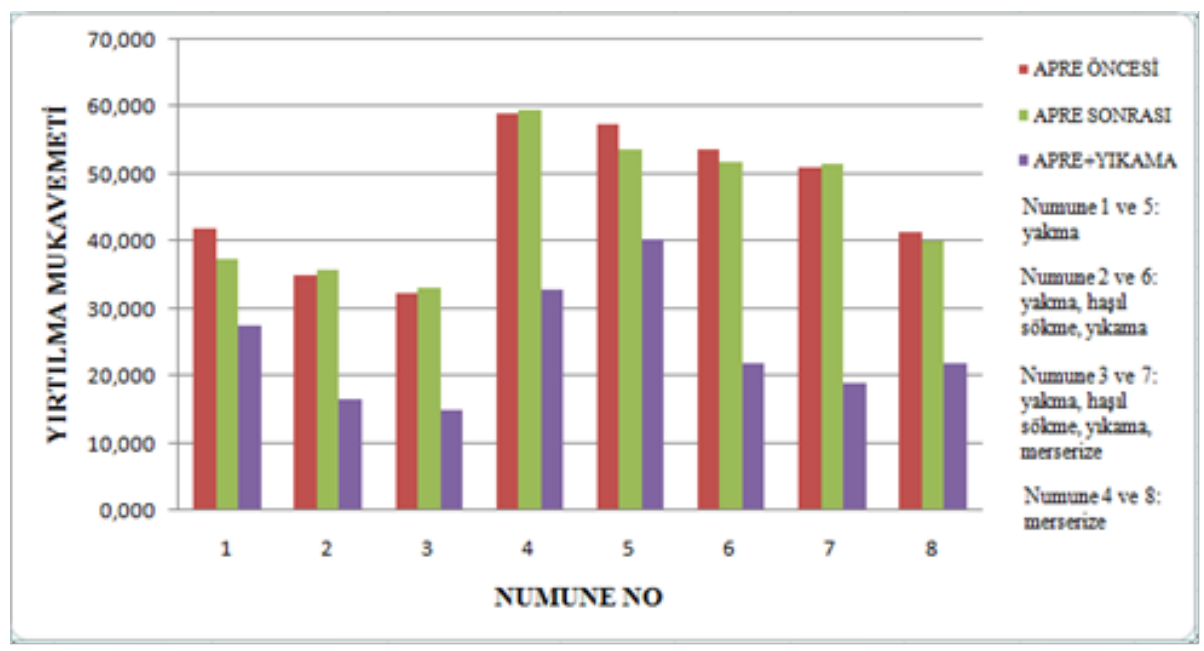

Şekil 3. Atk1 yırtılma mukavemeti değişimi

Yumuşaklık derecesi test sonuçlarının ortalama değerleri Çizelge 7'de, değişim ise Şekil 4'te verilmiştir.

Tüm numunelerde güç tutuşurluk apresinden sonra yumuşaklık bir miktar azalmış, kumaşlar sertleşmiştir. Ancak ön terbiyede sadece yakma uygulanan Numune 1 ve 5'de bu azalma diğerlerine göre daha fazla olmuştur.

Apreli kumaşlara yapılan yıkama sonrası ise genel olarak yumuşaklık değerlerinde artış gözlenmiştir.
Çizelge 7. Yumuşaklık Testi Sonuçları

\begin{tabular}{|c|c|c|c|}
\hline \multirow{2}{*}{$\begin{array}{c}\text { Numune } \\
\text { No }\end{array}$} & \multicolumn{3}{|c|}{ Yumușaklık Değerleri (kgf) } \\
\cline { 2 - 4 } & Apresiz & Apreli & $\begin{array}{c}\text { Apreli ve } \\
\text { ylkanmış }\end{array}$ \\
\hline 1 & 1,1474 & 2,6492 & 1,446 \\
\hline 2 & 1,2688 & 1,6994 & 1,7886 \\
\hline 3 & 1,3928 & 1,5570 & 1,7798 \\
\hline 4 & 0,9388 & 1,3792 & 1,0138 \\
\hline 5 & 0,7854 & 2,7850 & 1,4702 \\
\hline 6 & 0,9992 & 1,2474 & 1,2100 \\
\hline 7 & 0,9146 & 1,1698 & 1,2524 \\
\hline 8 & 1,3682 & 1,4852 & 1,3156 \\
\hline
\end{tabular}

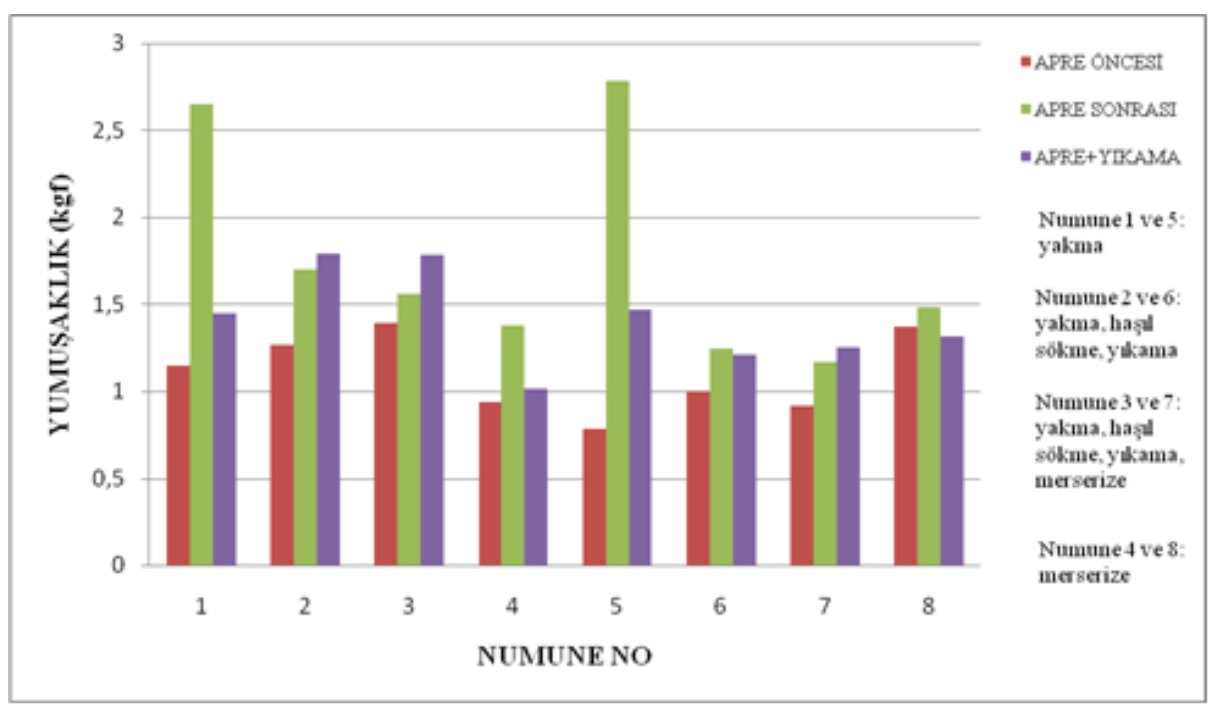

Şekil 4. Yumuşaklık değişimi 


\section{SONUÇLAR}

Çalışmada güç tutuşurluk apresi yapılmadan önce kumaşlara uygulanan güç tutuşurluk testinde bütün kumaşlarda alevlenme, delik veya parlama gözlemlenmiştir. Yani apre yapılmadan önce kumaşlar güç tutuşurluk testinden kalmıştır.

Apre uygulanan kumaşlarda ve apreden sonra yıkama yapılan kumaşlarda güç tutuşurluk testleri sonrasinda ise alevlenme, delik veya parlama gözlemlenmemiștir. Dolayısıyla numune kumaşlar güç tutuşurluk özelliğini kazanmıştır.

Çalıșma kapsamında kumaşlara güç tutuşurluk özelliği kazandırmanın kumaş özelliklerini etkileyip etkilemediğini tespit etmek için hava geçirgenliği, yırtılma mukavemeti ve yumuşaklık testleri yapılmıştır. Genel olarak apre ve yıkama işlemi sonrası numunelerin hava geçirgenliğinde düşüş gözlenmiş, ön terbiyede sadece yakma işleminin yapıldığı numunelerde ise bu düşüş çok daha belirgin olmuştur. Ön terbiyede yaş işlem görmeyen numunelerde, yaş bir işlem olan güç tutuşurluk apresinden sonra dokunun çekmesi ve sıklıkların değişmesi hava geçirgenlik değerlerinde belirgin düşüşe yol açmıştır.

Ayrıca yırtılma mukavemeti test sonuçlarına göre, güç tutuşurluk apresi ve sonrasında yapılan 5 tekrarlı rins yıkama işlemleri yırtılma mukavemeti açısından performans kaybına yol açmamıştır. Yumuşaklık derecesi test sonuçlarına göre ilk dört numunenin genel olarak daha sert olduğu söylenebilmektedir. Bunun nedeninin numunelerin atkılarında PBT kullanılması ile ilgili olabileceği düşünülmektedir. Numune 1 ve Numune 5'in apre sonrası yumuşaklığının diğerlerine göre daha fazla düşmesi, apre öncesi yaş işlem görmeyip sadece yakma işleminden geçmeleri ile açıklanabilir.

\section{KAYNAKLAR}

1. Horrocks, A.R., Anand, S.C., 2000. Handbook of Technical Textiles., Woodhead Publishing, Chapter 2, p:24-40, Cambridge England, ISBN 0-8493-1047-4.
2. Beyit, A., 2006. Nükleer, Biyolojik ve Kimyasal Korunma Amaçlı Koruyucu Tekstillerin Türkiye'de Üretilebilirliği. Yüksek Lisans Tezi, Marmara Üniversitesi, Tekstil Eğitimi Anabilim Dalı, İstanbul, 214.

3. Gemci, R., Gülşen, G., 2010. Güç Tutuşur Kumaş Üretiminde Bor Bileşiklerinin Kullanılması. Tekstil Teknolojileri Elektronik Dergisi, 4(1), 1-10.

4. Horrocks, A., 2011. Flame Retardant Challenges for Textiles and Fibres: New Chemistry Versus Innovatory Solutions. Polymer Degradation and Stability, 96, 377-392.

5. Covaci, A., Harrad, S., Abdallah, M.A., Nadeem, A., Law, R., Herzke, D., de Wit, C., 2011. Novel Brominated Flame Retardants: A Review of Their Analysis, Environmental Fate and Behaviour. Environment International. 37, 532-56. 10.1016/j.envint.2010.11.007.

6. Wang, B., Sheng, H., Shi, Y., Hu, W., Hong, N., Ge, H., Yu, X., Song, L., Hu, Y., 2015. Recent Advances for Microencapsulation of Flame Retardant. Polymer Degradation and Stability. 113, 96-109.

7. $\mathrm{Yu}$ Lu, S., Hamerton, I., 2002. Recent Developments in the Chemistry of HalogenFree Flame Retardant Polymers, Progress in Polymer Science, 27, 1661-1712.

8. Kalın, M.B., 2008. Tekstil Yüzeylerinin Yanmaya Karşı Dirençlerinin Arttırılması. Sütçü İmam Üniversitesi, Yüksek Lisans Tezi, Maraş, 86.

9. Ömeroğulları, Z., Kut, D., 2012. Tekstilde Güç Tutuşurluk. Uludağ Üniversitesi Mühendislik Mimarlık Fakültesi Dergisi, 17(1), 27-42.

10. Samatya, S., 2012. Kişisel ve Mülkiyet Koruyucu Teknik Tekstiller. Çukurova Üniversitesi Tekstil Mühendisliği, Yüksek Lisans Tezi, Adana, 418.

11. Ömeroğulları, Z., Kut, D., 2011. Doğal Yapıda Güç Tutuşur Madde Kullanımı ile Polyester Kumaşın Yanma Davranışının İncelenmesi. Tekstil ve Konfeksiyon, 21(4), 364-368.

12. Çakal, G.Ö., Göğabakan Z., Coşkun S., 2011. Borun Pamuklu Kumaşların Güç Tutuşurluğu Üzerindeki Sinerjik Etkisinin Araştırılması. Tekstil ve Konfeksiyon, 3, 265-271. 
13. Gültekin, B.C., Akalın, M., Yükseloğlu, S.M., 2013. SeaCell ${ }^{\circledR}$ Kumaşların Termal Özellikleri ve Güç Tutuşurluk Özelliklerinin İncelenmesi. Tekstil ve Konfeksiyon, 23(2), 12-15.

14. Ertekin, M., Kırtay, E., 2014. Aramid ve Güç Tutuşur Poliester Ring İplikleriyle Dokunmuş Kumaşların Yanma Davranışları ve Mekanik Özellikleri. Tekstil ve Konfeksiyon, 24(3), 259-265.

15. Bütüner, İ.F., 2014. Güç Tutuşurluk Bitim İşlemlerinde Kullanılan Ürünlerin Performans ve Sinerjetik Etkilerinin Karşılaştırılması. Ege Üniversitesi, Fen Bilimleri Enstitüsü, Tekstil Mühendisliği Anabilim Dalı, Yüksek Lisans Tezi, İzmir, 85.

16. Aksöz, Y., 2014. Selülozik Esaslı Kumaşlara Güç Tutuşur Özellik Kazandıran Yenilikçi Malzemeler Geliştirilmesi. Anadolu Üniversitesi, Fen Bilimleri Enstitüsü, İleri Teknolojiler Anabilim Dalı, Yüksek Lisans Tezi, 74.

17. Cayla, A., Rault, F., Giraud, S., 2016. PLA with Intumescent System Containing Lignin and Ammonium Polyphosphate for Flame Retardant Textile. Polymers, 8/2016, 331.

18. Avcı, H., Üreyen, M.E., Kılıç, A., Sağlam, A.E., Demir, A., 2019. Güç Tutuşur Polipropilen Polimeri ve Lif Uygulamalarında Son Gelişmeler ve Gelecek Beklentileri. Uludağ Üniversitesi Mühendislik Fakültesi Dergisi, 24(2), 609-632.

19. Şardağ, S., 2019. Farklı Oranlarda Pamuk, Tencel ve Meta-Aramid İçeren Güç Tutuşur Örme Kumaşhların Mukavemet ve Konfor Özelliklerinin İncelenmesi. Ulusal Çukurova Tekstil Kongresi-UÇTEK'2019, 26-27 Eylül, 1-8.

20. Akşit, A., Ünvar, Y., Özkayalar, S., Dindaroğlu, Y., 2019. Güç Tutuşur Tekstil Materyalleri için Alternatif Yaklaşımlar. Ulusal Çukurova Tekstil Kongresi-UÇTEK'2019, 2627 Eylül, 381-388.

21. Önder, Z., 2019. Örme Yatak Kumaşlarında Güç Tutuşurluk. Erciyes Üniversitesi, Fen Bilimleri Enstitüsü, Yüksek Lisans Tezi, Kayseri, 88.

22. Eyi, G., 2019. Pamuk ve Elastan Karışımlı Denim Kumaşların Borik Asit, Boraks Dekahidrat, Nano-SiO 2 , Triazin ve Fosfor
Bileşimleri Varlığında Güç Tutuşurluk Özelliklerinin İncelenmesi. Trakya Üniversitesi Fen Bilimleri Enstitüsü, Uygulamalı Bilimler ve Teknoloji Anabilim Dalı, Yüksek Lisans Tezi, Edirne, 103.

23. Kaynak, E., Üreyen, M. E., Koparal, A.S., Mutlu, A., 2020. Flame-Retardant Treatment of Wool and Wool-Rich Blends: A Study of Bath Composition, Journal of Engineered Fibers and Fabrics, 15, 1-10.

24. Karataş, E., 2021. Güç Tutuşurluk Apresinin Denim Kumaş Özelliklerine Etkisinin Araştırılması. Çukurova Üniversitesi, Tekstil Mühendisliği A̧nabilim Dalı, Yüksek Lisans Tezi, Adana, 83.

25. TS EN ISO 11612: 2015. Protective ClothingClothing to Protect agains Heat and Flame.

26. FlexiBurn Multipurpose Flammability Tester, James Heal, Ürün kataloğu, 2020.

27. TS 391 EN ISO 9237: 1999. TextilesDetermination of Permeability of Fabrics to Air.

28. TS EN ISO 13937-1, 2002. Textiles- Tear Properties of Fabrics- Part 1: Determination of Tear Force Using Ballistic Pendulum Method (Elmendorf).

29. ASTM D 4032-94, 1994. Standard Test Method for Stiffness of Fabric by the Circular Bend Procedure, ASTM International, West Conshohocken, PA.

30. Bakıc1, G.G., Kadem, F.D., 2017. Farkl1 Konstrüksiyondaki Pamuklu Denim Kumaşlarda Performans Özelliklerinin Araştırılması. Çukurova Üniversitesi, UÇTEK'2017, 28-29 Eylül 2017, Adana, 113-119.

31. TS 2791: 2003. Tekstil-Pamuklu Blucin (Denim) Kumaş. 
